\title{
Analysis of Landscape Patterns and the Trend of Forest Resources in the Three Gorges Reservoir Area
}

\author{
Wei Wang*, Ying Pu \\ Survey \& Planning Institute of State Forestry Administration, Beijing, China \\ Email: *didiwei1981@163.com
}

How to cite this paper: Wang, W. and $\mathrm{Pu}$, Y. (2018) Analysis of Landscape Patterns and the Trend of Forest Resources in the Three Gorges Reservoir Area. Journal of Geoscience and Environment Protection, 6, 181-192.

https://doi.org/10.4236/gep.2018.65015

Received: March 11, 2018

Accepted: May 22, 2018

Published: May 25, 2018

Copyright $\odot 2018$ by authors and Scientific Research Publishing Inc. This work is licensed under the Creative Commons Attribution International License (CC BY 4.0).

http://creativecommons.org/licenses/by/4.0/

\begin{abstract}
In this paper, first, based on landscape ecology theories, we respectively selected indexes from 4 aspects, area, edge, shape, and density, of the landscape type to describe the status of forest landscape patterns, and we established the stability index of landscape pattern (LSBI). Then, based on geo-statistical theories, we divided the forest in the reservoir area into 3990 grids of $4 \mathrm{~km} \times 4$ $\mathrm{km}$ using network technology and employing ordinary Kriging modelling to make trend surface analyses of the forest resources in the reservoir area. Finally, based on statistics principles, we used sampling theory to systematically extract 227 samples to obtain 7 periods of remote-sensing data from 1990a to 2012a. Then, we classified and extracted the forest in the sampling area using remote sensing, and we analysed each result with an Autoregressive Integrated Moving Average Model (ARIMA) time-series model. The results indicated the following: 1) the landscape structure of the reservoir area was primarily needle-leaved forest, broad-leaved forest and bush forest, and the mixed stands and bamboo stands were secondary; 2) the difference of the forest landscape pattern stability in the reservoir area, in all directions, was not significant, but the southern region was slightly more stable; and 3) the stability of the forest landscape pattern in the reservoir area increased from 1990a to 2012a. It kept increasing until 2016a. This study provides a theoretical basis for the reasonable management and decisions about the forest resources in the Three Gorges Reservoir Area. Meanwhile, it also explores methods for relevant research and has practical significance.
\end{abstract}

\section{Keywords}

Three Gorges Reservoir Area, Forest Resources, Landscape Pattern, Trend Analysis 


\section{Introduction}

Currently, there are numerous studies on landscape structure in the Three Gorges Reservoir Area [1] [2]. The present studies mainly focus on the classification of land use types, landscape fragmentation or vulnerability assessments, the changes and influence factors of the landscape pattern in some counties and districts and other aspects [3]-[8]. However, studies taking the whole forest in the Three Gorges Reservoir Area as a complete object, especially studies on the landscape status and succession direction of forest resources in the reservoir area, are lacking [9] [10] [11]. Therefore, we selected related and typical pattern indexes based on landscape ecology theories. First, we described the status of the landscape pattern of forest resources in the reservoir area. Then, we made a trend surface analysis on the forest in the reservoir area and explored its succession direction. This research studied the status of forest resources in the reservoir area on a macro scale. It also scientifically evaluated the spatial structure of forest resources and tracked the evolutionary changes in forest resources. This study provides a theoretical basis for reasonable management and decisions about the forest resources in the Three Gorges Reservoir Area. Meanwhile, it also explores methods for relevant studies and has practical significance.

\section{The General Situation of Research Area}

The Three Gorges Reservoir Area is located at an east longitude of $105^{\circ} 44^{\prime}$ $111^{\circ} 39^{\prime}$ and a northern latitude of $28^{\circ} 32^{\prime}-31^{\circ} 44^{\prime}$; the southeast and northeast border is the west of Hubei, the southwest border is Sichuan and Guizhou and its northwest border is Shanxi and Sichuan. It covers 27 counties (districts and cities). The land area is $5,807,200 \mathrm{hm}^{2}$. Chongqing city accounts for 4,626,500 $\mathrm{hm}^{2}$, and Hubei city accounts for $1,180,700 \mathrm{hm}^{2}$. The central parallel ridge and valley area is $1200-200 \mathrm{~m}$, and the lowest elevation, at Three Dou Ping, is $66 \mathrm{~m}$. In the reservoir area, valleys account for approximately $4.3 \%$ of the total area, hills account for $21.7 \%$ and mountains account for $74.0 \%$. The reservoir area is rich in species resources. It has 208 families, 1428 genera and 6088 species of vascular plants. The main vegetation types include needle-leaved forest, broad-leaved forest, mixed stand, shrub-grass and so on. The area of needle-leaved forest is the largest. Forest land area in the reservoir area is $3,241,700 \mathrm{hm}^{2}$, accounting for $55.82 \%$ of the total area. This area initially established the land ecological security system, which is primarily forest vegetation and combines forestry and prataculture [12] [13] [14] [15]. Cultivating the forest with a focus on water and soil conservation ensures the safe operation of the reservoir and the security of the ecological environment in the reservoir area.

\section{Methods}

\subsection{Selection of Landscape Pattern Index}

The landscape structure index is an important method for landscape spatial 
analysis, especially to reflect the structure and spatial allocation of study objects at the horizontal level. It can highly concentrate the landscape structure and simple quantitative information to allow for an interrelated measure of ecological processes and spatial structure. Selecting reasonable structure indexes has important effects on research. In this paper, we respectively selected indexes from 4 aspects: area, edge, shape, and density of the landscape types [16] [17] [18] [19]. To comprehensively consider the forest landscape pattern of the area, this research established a Landscape Stability Index considering the different aspects of the above landscape pattern. First, we need to make the indexes dimensionless and then calculate them. Finally, we analysed the horizontal structure of forest resources in the reservoir area (details in Table 1).

\subsection{Spatial Trend Analysis of Landscape Patterns}

Based on geo-statistical theories, we analysed the regional variation of landscape pattern stability with the ordinary Kriging interpolation method. The main principle of this method confirms a distance range, which affects the point value to be interpolated [20] [21] [22]. Then, we used the sampling points of this range to estimate the attribute values of neighbouring points. It takes the shape and size of landscape plaques, the spatial positions between them and other geometric characteristics and spatial structures into consideration. The result has high credibility, and it is a common method of statistical analysis.

$$
r(h)=\frac{1}{2 n} \sum_{i=1}^{n}\left(z\left(x_{i}\right)-z\left(x_{i}+h\right)\right)^{2}
$$

In the above equation, $h$ is the distance between two points; $n$ is the sample sizes; and $z$ is the analysis of attribute values.

The Kriging method relates probability and forecasting, as the probability value is inappropriate; even if there are a large number of samples, correct results cannot be found when determining the probability characteristics of a reasonable number of typical values of great significance [23] [24]. Therefore, using grid technology in the research, the reservoir area was divided into $4 \mathrm{~km} \times 4 \mathrm{~km}$, the smallest unit of division. The reservoir was completely divided into 3990 squares. The forest landscape stability index of each box was calculated in order to explore the forest landscape pattern trends in the reservoir area.

\subsection{Analysis of Landscape Patterns in Time}

\subsubsection{The Sampling Frame Design}

First, based on sampling theory, forest area coefficients of variation and systematic sampling were used with an estimation accuracy of $90 \%$. A certain number of samples were taken, and the process of sample pattern succession was analysed in order to reflect the succession of forest resources from the overall pattern of the region. In the research, different sizes of grid plots of forest area, estimating population variation coefficients, were analysed according to the system. 
Table 1. Horizontal structure of index formula and significance in reservoir area.

\begin{tabular}{|c|c|c|c|}
\hline Type & Index & Formula & Value range and significance \\
\hline \multirow{2}{*}{$\begin{array}{l}\text { Area } \\
\text { index }\end{array}$} & $\begin{array}{l}\text { PLAND } \\
\text { (Proportion } \\
\text { of Landscape } \\
\text { Types) }\end{array}$ & $\operatorname{PLAND}=\frac{\sum_{j=1}^{n} a_{i j}}{A} \times 100 \%$ & $\begin{array}{l}0 \leq \text { PLAND } \leq 100 \text {. The value tends to } 0 \text {, indicating } \\
\text { that plaque types in this landscape become very } \\
\text { scarce. If the value is equal to } 100 \text {, it indicates that the } \\
\text { total landscape is composed of only one type of pla- } \\
\text { que. It is one of the important indexes of } \\
\text { landscape structure. }\end{array}$ \\
\hline & $\begin{array}{l}\text { TCA } \\
\text { (Total Area } \\
\text { of Core Pla- } \\
\text { que) }\end{array}$ & $\mathrm{TCA}=\sum_{i=1}^{m} \sum_{j=1}^{n} a_{i j}^{c}\left(\frac{1}{10000}\right)$ & $\begin{array}{l}\text { TCA } \geq 0 \text {, no ceiling. When all positions within the } \\
\text { plaque are specified in the margin depth of the patch } \\
\text { circumference, TCA }=0 \text {; when the plaque shape is } \\
\text { simplified and the edge depth distance decreases, } \\
\text { TCA approaches the total landscape area. }\end{array}$ \\
\hline \multirow{2}{*}{$\begin{array}{l}\text { Edge } \\
\text { index }\end{array}$} & $\begin{array}{l}\text { TE } \\
\text { (Edge Total } \\
\text { Length) }\end{array}$ & $\mathrm{TE}=\sum_{k=1}^{m} e_{i K}$ & $\begin{array}{l}\mathrm{TE} \geq 0 \text {, no ceiling. The edge total length of landscape } \\
\text { type. The edge index can reflect the degree of } \\
\text { substance and energy exchange of the landscape type. } \\
\text { It has special value in research and conservation of } \\
\text { biodiversity. }\end{array}$ \\
\hline & $\begin{array}{c}\text { ED } \\
\text { (Edge } \\
\text { Density) }\end{array}$ & $\mathrm{ED}_{i}=\frac{p_{i}}{A}$ & $\begin{array}{l}\mathrm{ED} \geq 0 \text {, no ceiling. The ratio of total edge length }(\mathrm{Pi}) \\
\text { of plaque type } \mathrm{i} \text { and its area }(\mathrm{Ai}) \text { in the landscape. It } \\
\text { reveals the degree of landscape or type, which has } \\
\text { been divided by edge. It is also a direct reflection of } \\
\text { landscape fragmentation. }\end{array}$ \\
\hline \multirow{3}{*}{$\begin{array}{l}\text { Shape } \\
\text { index }\end{array}$} & $\begin{array}{c}\text { LSI } \\
\text { (Landscape } \\
\text { Shape Index) }\end{array}$ & $\mathrm{LSI}=\frac{0.25 \sum_{k=1}^{m} e_{i K}^{*}}{\sqrt{A}}$ & $\begin{array}{l}\text { LSI } \geq 1 \text {. It is the standard measure of landscape edge } \\
\text { shape. For a very simple perimeter (such as square), } \\
\text { LS is close to } 1 \text {; for a complex shape, it has no ceiling. }\end{array}$ \\
\hline & $\begin{array}{l}\text { PAFRAC } \\
\text { (Fractal }\end{array}$ & $\frac{2}{\left[N \sum_{i=1}^{m} \sum_{j=1}^{n}\left(\ln p_{i j}-\ln a_{i j}\right)\right]-\left[\sum_{i=1}^{m} \sum_{j=1}^{n} \ln p_{i j}-\sum_{i=1}^{m} \sum_{j=1}^{n} \ln a_{i j}\right]}$ & \multirow{2}{*}{$\begin{array}{l}1 \leq \text { PAFRAC } \leq 2 \text {. A fractal dimension greater than } 1 \\
\text { means a separation of } 2 \mathrm{D} \text { landscape mosaic and Euc- } \\
\text { lidean geometry. The complexity of patch shape in- } \\
\text { creases, and for highly complex edge shape, it is clos- } \\
\text { er to } 2 \text {. }\end{array}$} \\
\hline & Dimension) & {$\left[N \sum_{i=1}^{m} \sum_{j=1}^{n} \ln p_{i j}^{2}\right]-\left[\sum_{i=1}^{m} \sum_{j=1}^{n} \ln p_{i j}\right]$} & \\
\hline & $\begin{array}{c}\text { PD } \\
\text { (Plaque } \\
\text { Density) }\end{array}$ & $\mathrm{PD}=\frac{n_{i}}{A}(10000)(100)$ & $\begin{array}{l}\mathrm{PD} \geq 0 \text {, no ceiling. Plaque density refers to the } \\
\text { number of plaques per unit area. It benefits the } \\
\text { comparison between different landscapes. If the total } \\
\text { landscape area is determined, then the density and } \\
\text { number of plaque convey the same information. }\end{array}$ \\
\hline $\begin{array}{l}\text { Density } \\
\text { index }\end{array}$ & $\begin{array}{l}\text { MPS } \\
\text { (Mean Pla- } \\
\text { que Size) }\end{array}$ & $\mathrm{MPS}=\frac{\sum_{i=1}^{n} a_{i j}}{n} \times\left(\frac{1}{10000}\right)$ & $\begin{array}{l}\text { MPS } \geq 0 \text {. The distribution range of the MPS value in } \\
\text { landscapes restricts the image or map scope and the } \\
\text { selection of the smallest plaque size of the landscape. } \\
\text { In addition, MPS can refer to the degree of landscape } \\
\text { fragmentation. }\end{array}$ \\
\hline & $\begin{array}{c}\text { ENN } \\
\text { (Mean } \\
\text { Nearest } \\
\text { Distance) }\end{array}$ & $\mathrm{ENN}=h_{i j}$ & $\begin{array}{l}\text { ENN }>0 \text {, no ceiling. It is equal to the distance of the } \\
\text { nearest and the same type of plaque, based on the } \\
\text { shortest distance between edge and edge. When the } \\
\text { nearest neighbour distance decreases, the value of } \\
\text { ENN tends towards } 0 \text {. It reflects the isolation and } \\
\text { distribution degree of landscape type. }\end{array}$ \\
\hline $\begin{array}{l}\text { Stability } \\
\text { index }\end{array}$ & $\begin{array}{l}\text { LSBI } \\
\text { (Landscape } \\
\text { stability } \\
\text { index) }\end{array}$ & $\mathrm{LSBI}=\frac{\mathrm{PLAND}+\mathrm{TCA}+\mathrm{TE}+\mathrm{PAFRAC}+\mathrm{ENN}}{5} \times 100 \%$ & $\begin{array}{l}0 \leq \mathrm{LSBI} \leq 100 \text {. Summarizes the ecological } \\
\text { significance of all the selected indices. When the } \\
\text { landscape area is greater, the edge perimeter is longer, } \\
\text { and the shape is more complex. When the isolation } \\
\text { degree of landscape is smaller, it means the landscape } \\
\text { pattern is more stable. }\end{array}$ \\
\hline
\end{tabular}


Then, 227 forest resource monitoring plots were arranged in the reservoir area, the final plot area was $4 \mathrm{~km} \times 4 \mathrm{~km}$ (Figure 1), and the plot interval was $16 \mathrm{~km}^{2}$ (details in Table 2).

Then, using remote sensing technology, 7 periods (1990a, 1994a, 1998a, 2002a, 2006a, 2010a, and 2012a) of remote-sensing data were used to classify and extract information. Object-oriented classification and unsupervised classification methods were used; combined with the forestry management information and previous monitoring results, the spatial distributions of sampling data of regional forest resources from 1990a-2012a were obtained.

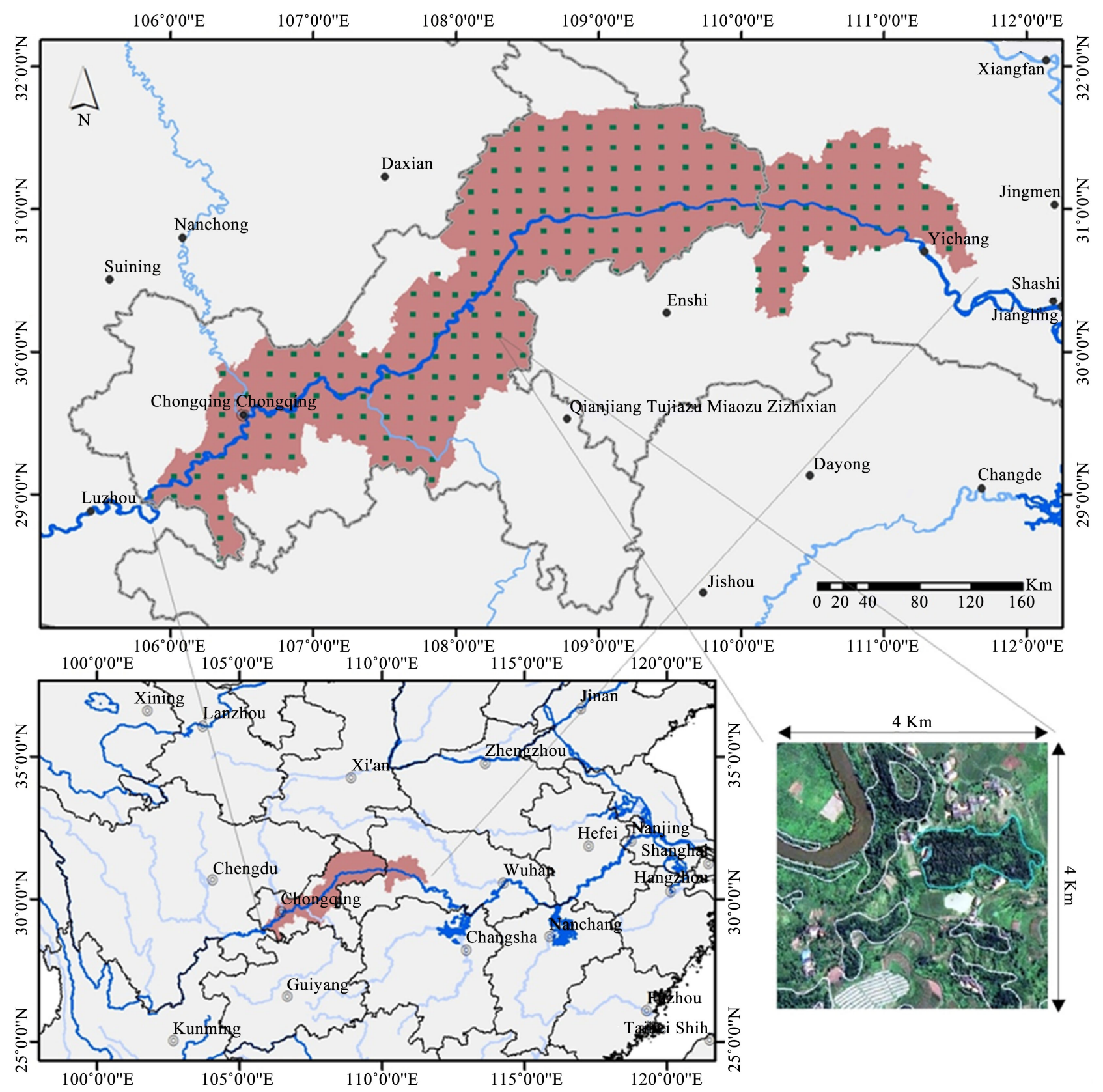

Figure 1. Schematic diagram of distribution plots in the sampling area. 
Table 2. Formulas and explanation.

\begin{tabular}{|c|c|c|}
\hline Projects & The formulas and calculation results & Parameters \\
\hline The overall coefficient & $\sqrt{\frac{1}{n-1} \sum_{i=1}^{n}\left(y_{i}-\bar{y}\right)^{2}}$ & $n$-the overall grid number; \\
\hline & $c=\frac{\sqrt{n-1}}{\bar{y}}$ & $\begin{array}{l}y_{i} \text {-forest area of the ith grid; } \\
\bar{y} \text {-average number of total }\end{array}$ \\
\hline Sample number $n$ & $n=\frac{t^{2} C^{2}}{E^{2}}=\frac{t^{2} \frac{S^{2}}{\bar{y}^{2}}}{\frac{\Delta^{2}}{\bar{y}^{2}}}=\frac{t^{2} S^{2}}{\Delta^{2}}$ & $\begin{array}{c}\text { forest area; } \\
S \text {-the overall variance; } \\
E \text {-relative error; } \\
\Delta \text {-absolute error; }\end{array}$ \\
\hline The sample spacing $D$ & $D=\sqrt{\frac{A}{n}}$ & $\begin{array}{c}A \text {-the total area of the reservoir; } \\
t \text {-security probability } 95 \%\end{array}$ \\
\hline
\end{tabular}

\subsubsection{Analysis of Time Series Based on ARIMA Model}

The long-term trends in time series can reflect forest landscape pattern development directions in the reservoir area. Over a longer period of time, trends can be an approximate straight line continuing upward, downward or smooth. Trends can also reflect a similar index trend or other curve trend. Once formed, trends will continue for a long time; therefore, they have important practical significance for prediction research. The ARIMA model takes data sequences that were formed by forecast objects over the passage of time as a random sequence, using some of the mathematical model to describe the sequence. Once identified, this model can predict the future value from the last value of the time series [25] [26] [27] [28].

$$
\left(1-\sum_{i=1}^{p} \phi_{i} L^{i}\right)(1-L)(1-L)^{d} X_{t}=\left(1+\sum_{i=1}^{q} \theta_{i} L^{i}\right) \varepsilon_{t}
$$

In the above equation, $p$ is the autoregressive order; $d$ is the number of differential; $q$ is the moving average order; and $\mathrm{L}$ is the Lag operator.

\section{Results}

\subsection{Present Situation}

The results for characteristics of landscape pattern showed that:

1) With respect to landscape area, (1) forest types: the main landscape types were coniferous forest, broadleaf forest, shrub forest; the secondary landscapes were mixed forest and bamboo forest. The mixed forest area was larger than the area of the shrub forest (TCA 569). This indicated that shrub forest has a relatively low degree of polymerization. (2) Origin of forest: natural forest dominated in the landscape (PLAND 71.4\%), and plantation forest was less obvious. (3) Age group: young forest and middle-aged forest dominated in the landscape (PLAND 83.8\%). The nearly mature forest, mature forest and over-mature forest total area was less.

2) With respect to landscape edge, although the area of bamboo was less than mixed forest, the edge was longer (TE 426). This indicated that bamboo was better than mixed forest in exchanging material and energy. Other variations 
in landscape type tended to have the same representation with respect to landscape area.

3) With respect to landscape shape, bamboo forest, shrub forest, and broad-leaved forest have complex shapes (PAFRAC 1.40, 1.38, 1.37), and the natural forest shape (PAFRAC 1.45) is more complex than the plantation. This indicated that natural forest has stronger adaptability and anti-jamming abilities than plantations.

4) With respect to landscape density, although the area of bamboo was small, it has a large number of patches. Therefore, it was greater than mixed forest, with respect to density (PD 2.3). Plantation forest density was close to that of natural forest, and it has a large number of patches. This indicated that landscape structure stability of plantation was lower than that of natural forest (details in Table 3 ).

\subsection{Spatial Trends}

The results for spatial trends of landscape patterns showed that:

1) In the southeast and northwest directions (Figure 2), the trend line was slightly bent at both ends, higher in the middle, and totally flat. This indicated that the east-west direction (X axis) and the north-south direction ( $\mathrm{Y}$ axis) in the landscape pattern have no significant difference.

Table 3. The results of landscape pattern index.

\begin{tabular}{|c|c|c|c|c|c|c|c|c|c|}
\hline \multirow{3}{*}{ Forest type } & \multicolumn{2}{|c|}{ Area index } & \multicolumn{2}{|c|}{ Edge index } & \multicolumn{2}{|c|}{ Shape index } & \multicolumn{3}{|c|}{ Density index } \\
\hline & PLAND & TCA & $\mathrm{TE}$ & ED & LSI & PAFRAC & $\mathrm{PD}$ & MPS & ENN \\
\hline & $\%$ & $100 \mathrm{ha}$ & $100 \mathrm{~km}$ & $\mathrm{~m} / \mathrm{ha}$ & - & - & 100 ha & ha & $\mathrm{m}$ \\
\hline Coniferous & 51.0 & 2614 & 3863 & 136 & 1.73 & 1.36 & 11.9 & 58.0 & 259 \\
\hline Broadleaf & 27.2 & 1669 & 2020 & 71 & 1.69 & 1.37 & 7.1 & 28.9 & 330 \\
\hline Mixed & 7.9 & 569 & 402 & 14 & 1.79 & 1.33 & 0.7 & 64.5 & 340 \\
\hline Bamboo & 3.2 & 18 & 426 & 15 & 1.69 & 1.40 & 2.3 & 8.5 & 488 \\
\hline Shrub & 10.8 & 422 & 804 & 28 & 1.66 & 1.38 & 3.0 & 25.6 & 397 \\
\hline Plantation & 28.6 & 1044 & 2578 & 96 & 1.65 & 1.38 & 10.7 & 28.9 & 321 \\
\hline Natural & 71.4 & 4703 & 4633 & 172 & 1.75 & 1.45 & 14.8 & 69.8 & 258 \\
\hline Young & 39.8 & 1821 & 2715 & 101 & 1.68 & 1.38 & 10.1 & 36.5 & 298 \\
\hline Middle age & 44.0 & 1778 & 1028 & 119 & 1.72 & 1.36 & 10.9 & 33.9 & 277 \\
\hline Nearly mature & 12.0 & 318 & 247 & 38 & 1.71 & 1.36 & 3.5 & 20.0 & 412 \\
\hline Mature & 3.7 & 106 & 3186 & 9 & 1.73 & 1.37 & 0.8 & 17.6 & 655 \\
\hline Over-mature & 0.5 & 11 & 34 & 1 & 1.64 & 1.36 & 0.1 & 18.1 & 1589 \\
\hline
\end{tabular}




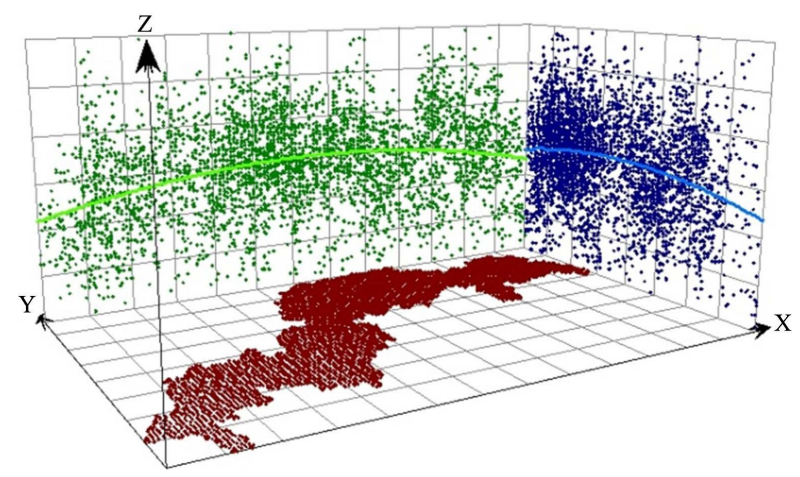

Figure 2. Trend analysis on direction graph (2012a).

2) With respect to the distribution (Figure 3), the landscape stability index (LSBI) was distributed in the range of $0-80$, but the main focus was in the range of 20 - 50, with a normal distribution. The relatively high value of LSBI was distributed in the southern region slightly more. This indicated that the stability of the forest landscape pattern was slightly higher in the south than in the north.

The ordinary Kriging interpolation was a good method for expressing the regular pattern (Figure 4 and Figure 5).

\subsection{Time Trends}

The results for time trends of landscape pattern showed the following (Table 4): the average mean absolute percentage error (Mean-APE) was $3.782 \%$, and the values ranged from $0.457 \%-5.569 \%$. The maximum absolute percentage error (Max-APE) was $4.674 \%$, and the values ranged from $1.299 \%-8.276 \%$. In the 95\% prediction interval, this Max-APE was $7.989 \%$. This indicated that there was nearly $4 \%$ of uncertainty predicted in the result. The greatest uncertainty was approximately $5 \%$, and the most extreme uncertainty was approximately $8 \%$. The ARIMA method was a good method for expressing the regular time-series pattern.

Using ordinary Kriging interpolation, the study carried the 1990a-2012a results into 2016a results. The results for the time trends of the landscape pattern showed the following (Figure 6):

1) From 1990a-2016a, the stability of the forest landscape pattern increased continuously, and the range of increase was significant.

2) With respect to direction, the southern region increased greatly, and there was no difference in the east-west direction.

\section{Discussion and Conclusion}

Through this research, the characteristics of the spatial distribution of forest resources were found and understood in the reservoir area. It was shown that the main landscape types were coniferous forest, broadleaf forest, and shrub forest and that the secondary landscape types were mixed forest and bamboo forest. 
Table 4. The fitting results using the ARIMA time series model.

\begin{tabular}{ccccccccccccc}
\hline \multirow{2}{*}{ Fit Statistic } & Mean & SE & Minimum & Maximum & \multicolumn{9}{c}{ Percentile } \\
\cline { 8 - 12 } & & & & & 5 & 10 & 25 & 50 & 75 & 90 & 95 \\
\hline Stationary R-squared & 0.684 & 0.237 & 0.000 & 0.979 & 0.208 & 0.327 & 0.543 & 0.749 & 0.876 & 0.926 & 0.943 \\
R-squared & 0.924 & 0.037 & 0.000 & 0.979 & 0.708 & 0.827 & 0.843 & 0.949 & 0.976 & 0.986 & 0.989 \\
RMSE & 3.782 & 3.209 & 0.117 & 28.155 & 0.454 & 0.648 & 1.675 & 3.098 & 5.047 & 7.975 & 9.708 \\
Mean-APE & 3.555 & 0.347 & 0.457 & 5.569 & 0.746 & 1.305 & 2.868 & 3.660 & 4.600 & 5.073 & 5.219 \\
Max-APE & 4.674 & 1.013 & 1.299 & 8.276 & 1.594 & 2.523 & 3.149 & 4.554 & 6.524 & 6.999 & 7.989 \\
MAE & 2.696 & 2.286 & 0.081 & 19.614 & 0.322 & 0.443 & 1.174 & 2.176 & 3.558 & 5.871 & 6.919 \\
Max-AE & 5.659 & 4.881 & 0.154 & 40.781 & 0.726 & 0.986 & 2.480 & 4.450 & 7.543 & 12.092 & 14.981 \\
Normalized BIC & 2.514 & 1.838 & 0.739 & 7.231 & 1.021 & 1.312 & 1.587 & 2.818 & 3.794 & 4.708 & 5.102 \\
\hline
\end{tabular}

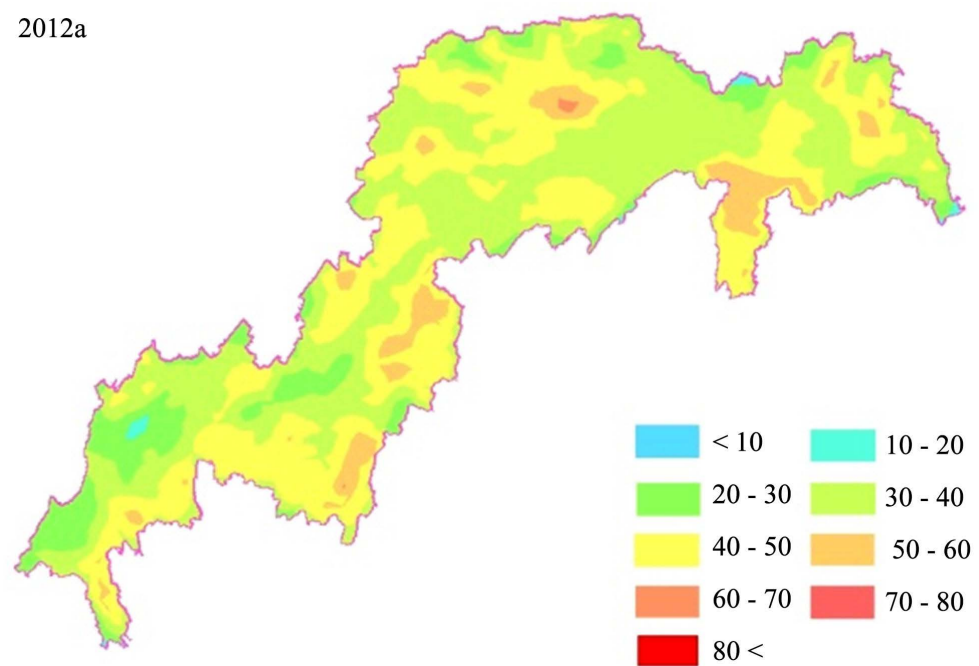

Figure 3. The distribution graph (2012a).

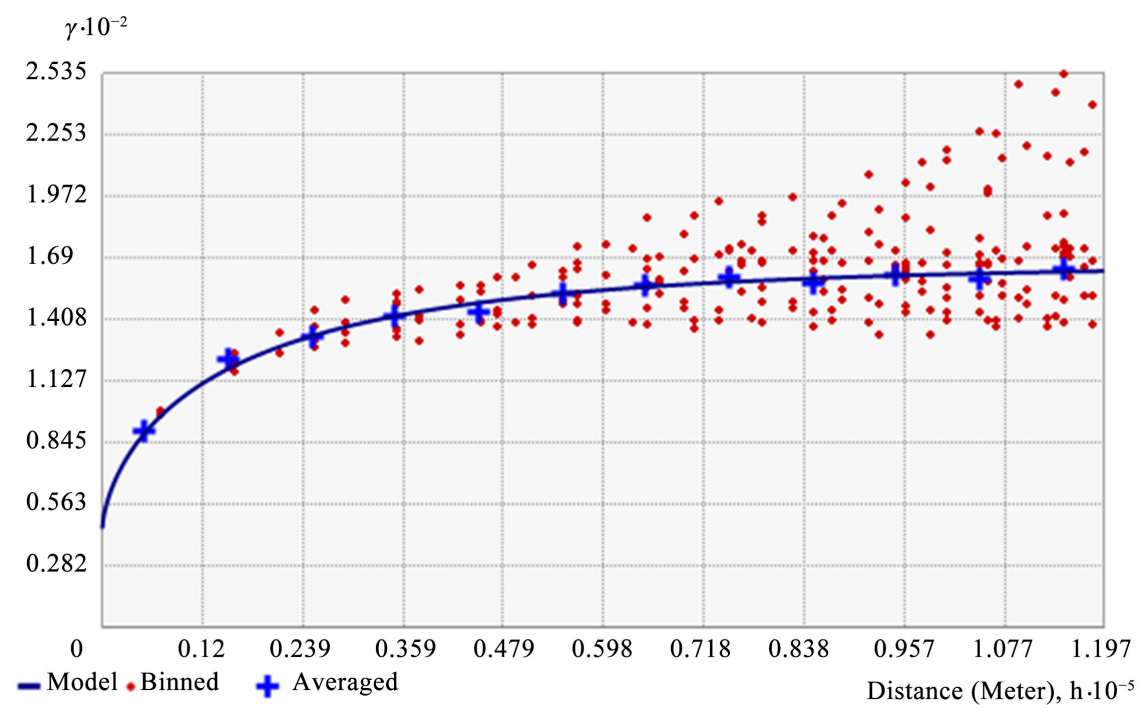

Figure 4. Ordinary semi-variation of kriging. 


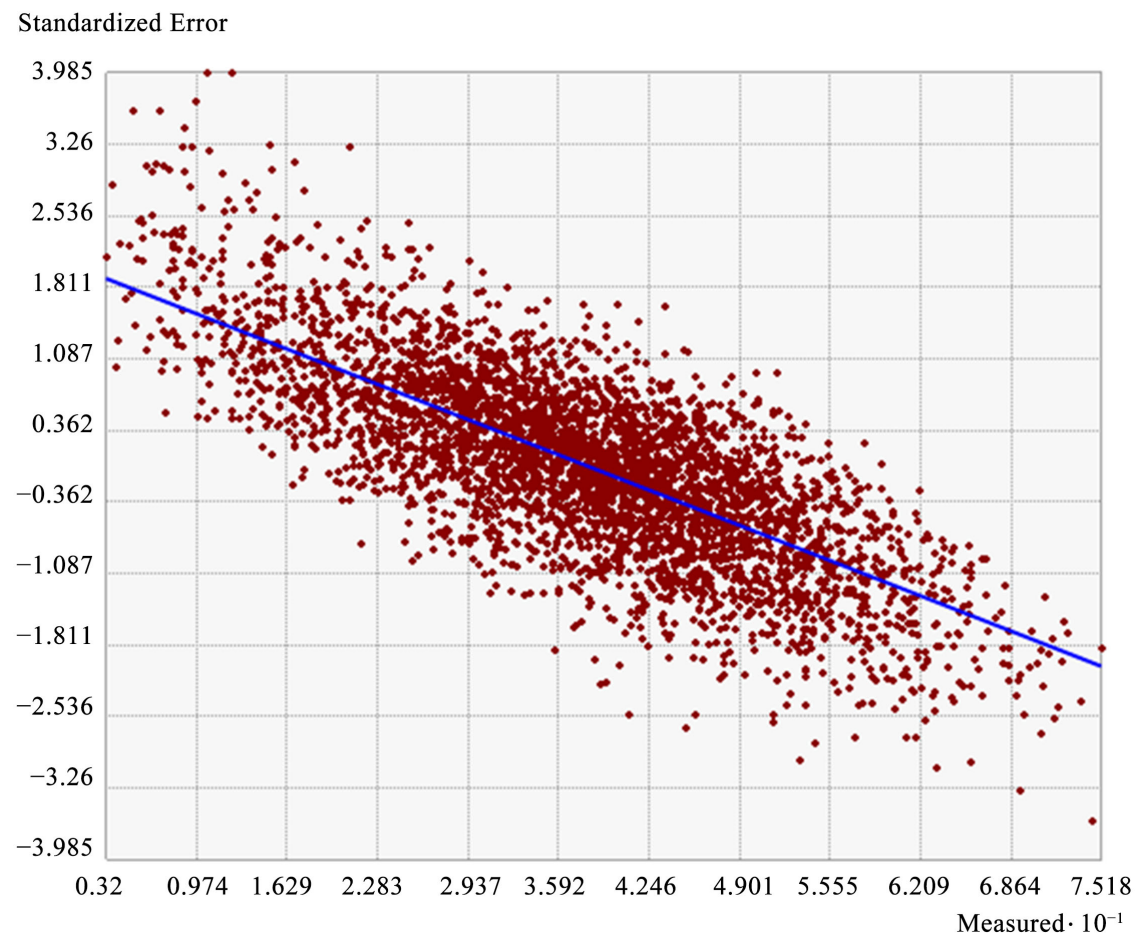

Figure 5. The standard deviation distribution of Kriging.

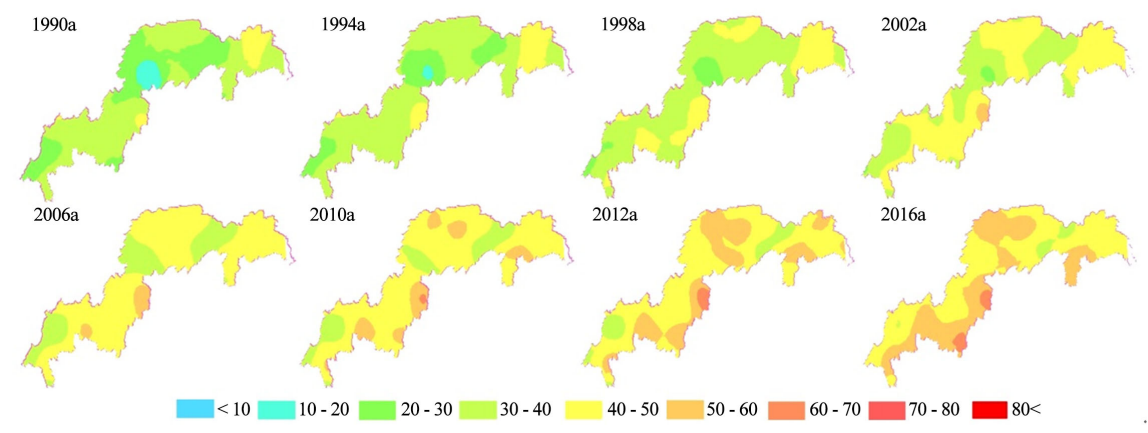

Figure 6. The distribution of time series on landscape (1990a-2016a).

The east-west direction and the north-south direction in the landscape pattern did not differ significantly. The stability of forest landscapes was slightly higher in the south. The ordinary Kriging interpolation was a good method for expressing the regular pattern.

A sampling technique was used in the study. To ensure accuracy, this method reduced a lot of work, such as data preprocessing and analysis. Further, it could reduce the need for research funding. At the same time, using models for time-series analysis, the stability of the forest landscape pattern increased continuously, and the range of increase was significant from 1990a-2016a. The results were reliable, based on the analysis of the fitting results. Therefore, based on the results, these methods we selected were effective and provided a theoretical principle for further research. 
To improve the ecological benefits of forest area, we should start from the following points:

1) We should gradually increase the mixed forest and bamboo forest areas and increase the proportion of these two types of areas in the landscape. It would be appropriate to expand the existing bamboo plaque area.

2) In certain areas, we should increase the degree of polymerization of shrub patches.

3) Previous research has shown that, generally, the ecological benefit of natural forest is higher than that of plantation forest. Thus, forest resources will be most beneficial if we keep natural forest and plantation landscape structure in the reservoir area, gradually reduce the proportion of plantation forest, and provide populations of natural forest.

4) If we gradually increase the proportion of nearly mature forest, mature forest and over-mature forest totals, it will promote stability in the forest landscape pattern in the reservoir area.

\section{References}

[1] Shao, H.Y., Xian, W. and Zhou, W.C. (2005) Landscape Pattern at Different Elevations Above Sea Level in Three Gorges Area Using 3S. Bulletin of Soil and Water Conservation, 25, 54-57.

[2] Xian, W., Shao, H.Y. and Zhou, W.C. (2007) Research on the Landscape Pattern of Slopes with Different Gradients and Directions in the Area of Three Gorges Area based On 3S. Chinese Journal of Eco-Agriculture, 15, 140-144.

[3] Chen, D., Zhou, Q.G., Hang, Y.A., et al. (2012) Analysis of Landscape Pattern in Three Gorges Reservoir Area Based on RS and GIS. Journal of Chongqing Technology Business University (Nat Sci Ed), 29, 69-73.

[4] Yuan, C.W., Wu, B.G., Shi, Y.H., et al. (2007) A Study on RS and GIS-Based Forest Resources Structure and Spatial Distribution Pattern in the Three Gorges Reservoir Region in Western Hubei. Journal of Northwest Forestry University, 22, 185-189.

[5] Zhang, Y.X., Yan, N.P., Xia, C.Z., et al. (2013) Study on Evolution of Forest Landscape Fragmentation of Three Gorges Reservoir Area Based on Multi-Remote Sensing Images. Journal of Central South University of Forestry \& Technology, 33, 1-6.

[6] Wang, L.Q., Xi, C.Y., Fu, Q., et al. (2010) Landscape Pattern-Based Eco-Environment Vulnerability Assessment of Three Gorges Reservoir Area. Research of Environmental Sciences, 2, 1268-1273.

[7] Ding, S.Y. and Liang, G.F. (2004) Landscape Pattern Change of Regional Wetland along the Yellow River in Henan Province in the Last Two Decades. Acta Geographica Sinica, 59, 653-660.

[8] Gao, Q. (2005) Landscape Changes and Human Activities in Three Gorges Reservoir Area: The Case of Yunyang County. Acta Ecologica Sinica, 25, 2499-2506.

[9] Wagn, W. and Dang, Y.F. (2013) Growth Model of Masson Pine Natural Forest in the Three Gorges Reservoir Area. Journal of Northwest Forestry University, 28, 125-128.

[10] Jiang, H.H., Li, J.H. and Fan, W.Y., et al. (2009) Landscape Pattern Change and Its Simulation Forecast in Zigui County of Three Gorges Reservoir Area. Chinese 
Journal of Applied Ecology, 20, 474-479.

[11] Li, Y., Zhag, Y.Z. and Zhag, S.W. (2002) The Landscape Pattern and Ecologic Effect of the Marsh Changes in the Sanjiang Plain. Scientia Geographica Sinica, 12, 677-682.

[12] Zhang, J.T., Qiu, Y. and Zheng, F.Y. (2000) Quantitative Methods in Landscape Pattern Analysis. Journal of Mountain Science, 18, 346-352.

[13] Ge, F.L., Li, W.F. and Chen, Q.W. (2008) Review of Landscape Change and Its Ecological Impacts. Ecology and Environment, 17, 2511-2519.

[14] Sun, X.J., Xiao, W.F. and Liu, X.D. (2014) Quantitative Analysis of Forest Landscape Security Patterns at the Three-Gorges Reservoir Area. Forest Research, 27, 836-840.

[15] Li, X.Z., Bu, R.C., Chang, Y., et al. (2004) The Response of Landscape Metrics against Pattern Scenarios. Acta Ecologica Sinica, 24, 123-133.

[16] Forman, R.T.T. and Godron, M. (1986) Landscape Ecology. John Wiley Sons, New York.

[17] Fman, J.K. (2001) Fifty Years of Landscape Transformation in Managed Forests of Southern Finland Scand. Forest Research, 16, 44-53.

[18] Lowicki, D. (2008) Land Use Changes in Poland during Transformation Case Study of Wielkopolska Region. Landscape and Urball Planning, 87, 279-288. https://doi.org/10.1016/j.landurbplan.2008.06.010

[19] Castillo, M.M. (2010) Land Use and Mpography as Predictors of Nutrient Levels in a Tropical Catchment. Linmologica, 40, 322-329.

[20] Conway, T.M. (2007) Impervious Surface as an Indicator of $\mathrm{pH}$ and Specific Conductance in the Urbanizing Coastal Golle of New Jersey, USA. Journal of Environmental Management, 85, 308-316. https://doi.org/10.1016/j.jenvman.2006.09.023

[21] Liu, Y., Wang, J. and Long, H. (2010) Analysis of Arable Land Loss and Its Impact on Rural Sustainability in Southern Jiangsu Province of China. Journal of Environmental Management, 91, 646-653. https://doi.org/10.1016/j.jenvman.2009.09.028

[22] Sun, J., Wang, X., Chen, A., et al. (2011) NDVI Indicated Characteristics of Vegaation Cover Change in China's Metropolises over the Last Three Decades. Environmental Monitoring and Assessment, 179, 1-14.

[23] Gething, W.P., Atkinson, P.M., Noor, A.M., et al. (2007) A Local Space-Time Kriging Approach Applied to a National Outpatient Malaria Data Set. Computers and Geosciences, 233, 1337-1350. https://doi.org/10.1016/j.cageo.2007.05.006

[24] Huerta, G., Sans, B. and Stroud, J.R. (2004) A Spatial Temporal Model for Mexico City Zone Levels. Journal of the Royal Statistical Society Series, 53, 231-248. https://doi.org/10.1046/j.1467-9876.2003.05100.x

[25] Pang, W., Christakos, G. and Wang, J. (2009) Comparative Spatial Temporal Analysis of Fine Particulate Matter Pollution. Environmetrics, 21, 1002-1007.

[26] Jia, J.S., Zhao, J.Z., Deng, H., et al. (2010) Ecological Footprint Simulation and Prediction by ARIMA Model-A Case Study in Henan Province of China. Ecological Indicators, 10, 538-544. https://doi.org/10.1016/j.ecolind.2009.06.007

[27] Anselin, L. (1995) Local Indicators of Spatial Association-LISA. Geographical Analysis, 27, 93-115. https://doi.org/10.1111/j.1538-4632.1995.tb00338.x

[28] Deutsch, S.J. and Ramos, J.A. (1986) Space-Time Modeling of Vector Hydrologic Sequences. Water Resources Bulletin, 22, 967-980.

https://doi.org/10.1111/j.1752-1688.1986.tb00768.x 